\title{
Charity vs. government health care
}

\author{
Gilbert Berdine MD
}

\begin{abstract}
Part 3 of this series on sustainable health care discusses charity as a market phenomenon. Charity is explained as a result of the Law of Marginal Utility and the limitation of scare resources. Charity is contrasted with government health care or public health care. Charity and government health care are driven by different incentives. Charities compete for limited donations leading to improved relief of suffering at lower cost over time. Government health care acts like all monopolies and delivers a declining quality of output at ever increasing cost.
\end{abstract}

Keywords: charity, free market, marginal utility, health care economics

Two prior articles set the stage for the current analysis. The first article Affordable Health Care ${ }^{1}$ discussed health care that was sustainable in terms of economics. The second article, Sustainable Health Insurance ${ }^{2}$ discussed how insurance can handle outlier risks in a way beneficial to everyone. The current article will discuss the differences between charity and government health care. The purpose of both systems is to provide "basic" health care to the "poor" members of society, but charity leads to different incentives than government health care and, therefore, to different outcomes. Charity is, by its structure, limited in scope and, therefore, sustainable, while government health care has no limits to scope and will grow until it consumes all available resources.

\section{LaW of Marginal Utility}

Figure 1 shows the Law of Marginal Utility. The marginal utility curve has negative slope. This means

Corresponding author: Gilbert Berdine Contact Information: Gilbert.berdine@ttuhsc.edu DOI: 10.12746/swrccc.v6i26.506 that as people possess greater amounts of something, the added value of the next added unit of quantity decreases. The marginal utility curve in this example is a straight line, but the negative slope need not be constant at all quantities. There are several important features of this figure. The Total Utility and the Marginal Utility must be equal for a quantity of one where the units of quantity represent the smallest possible amount that may be owned. As additional units of quantity are added, the Total Utility is increased by the Marginal Utility for that quantity. The quantity where the Marginal Utility crosses 0 Utility is the quantity of

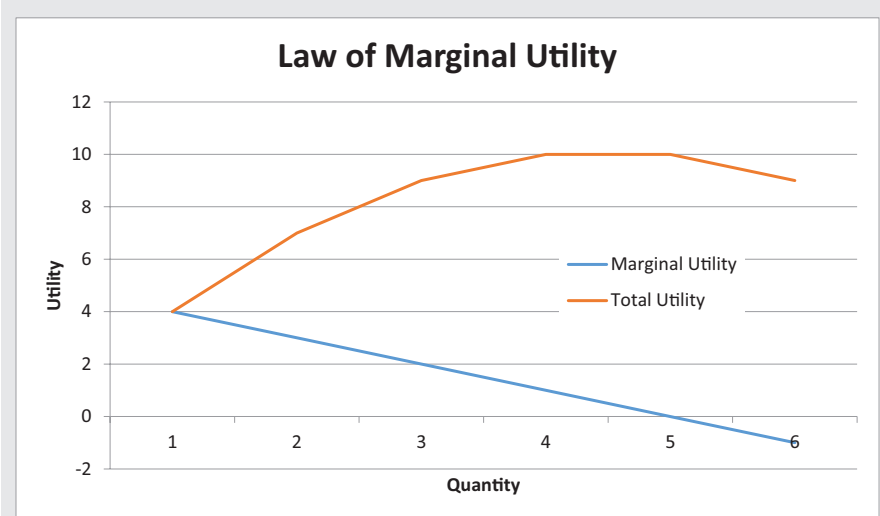

Figure 1. 
maximum Total Utility or satiety. Further increases in quantity have negative Marginal Utility and decrease Total Utility. Excess that cannot be consumed must be stored for future use and storage imposes costs. In some situations, it is cheaper to destroy excess quantity than to store it. Aristotle noted that, "For, whereas external goods have a limit, like any other instrument, and all things useful are of such a nature that where there is too much of them they must either do harm, or at any rate be of no use, . . . ${ }^{3}$ An example would be a flare stack in an oil well.

As an example of the Law of Marginal Utility in health care, consider a visit to the physician. One visit to the physician allows the diagnosis of new problems, the treatment of existing problems, and instructions for health maintenance. Additional visits add value only to the extent that new problems appear, existing problems require adjustments in treatment, and additional maintenance is useful. At some point, additional visits become a nuisance adding costs of transportation, lost time from work, and other opportunity costs of time spent during the additional visit. A single screening colonoscopy every 10 years might add diagnostic value, but a screening colonoscopy every day would be wasteful and introduce unnecessary risks. This negative utility is sometimes seen with fragmented care leading to unnecessary duplication of tests. ${ }^{4}$

\section{Competing Utilities for Scarce Resources}

The Law of Marginal Utility causes us to pursue strategies that yield the maximum utility for an expenditure of time and resources. ${ }^{5}$ The next tier of strategies will necessarily yield lower Marginal Utility, greater marginal costs, or both. Resources spent on health care are necessarily not available for some other purpose, including saving for retirement or future disability, capital investment to increase future economic output, and leisure. These other uses also have Marginal Utility curves. Spending more on health care moves us to the right on the Marginal Utility Curve for health care, but moves us to the left on the Marginal Utility Curve for everything else. Note that the gain in Utility by moving to the right is necessarily less than

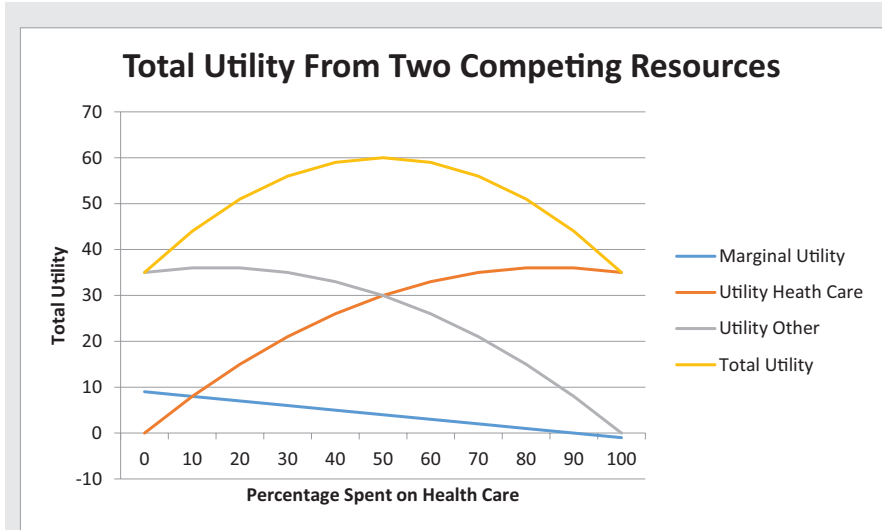

Figure 2.

the loss in Utility by an equal movement to the left on the same curve. It is quite possible that small gains in utility in one area come at the expense of large losses in utility in some other area due to limited resources.

In Figure 2 we see the effect of marginal utility on the total utility from two valuable things competing for limited resources. In this example, we have Health Care and Other. In this hypothetical example the Marginal Utility Curve for both health care and other are the same. As expenditure on health care increases, we get more health care, but less other. Examination of Figure 2 shows that the satiety or maximal utility from health care occurs at $90 \%$ spent on health care, and the satiety or maximal utility from other occurs at $10 \%$ spent on health care in this hypothetical example. Spending more than $90 \%$ on health care decreases the utility from health care as well as makes less available for spending on other. Spending less than $10 \%$ on health care decreases the utility from both health care and other. The maximal utility must occur somewhere between the two satiety points. We see from Figure 2 that in this hypothetical example the maximal total utility-obtained as the sum of the utilities for health care and other-occurs in the middle at $50 \%$ expenditure.

A utilitarian society would look at Figure 2 and decide that $50 \%$ expenditure on health care was optimal for total utility. Public policy in general would be a process of plotting the individual utility curves, 
summing all the constituent utility curves to calculate a total utility curve, plotting the total utility curve, and choosing the distribution of expenditures that were associated with the maximal utility on the graph. The problem with the utilitarian approach is that the exact values for marginal utility for health care and other are not known. We cannot calculate what percentage spent on health care will yield the maximal utility. We can use theory to predict what happens in qualitative ways, but we can only observe what people choose.

In a free market, the market participants will make individual choices based on what has greatest value for them at that moment in time. Exchanges will occur when opportunities arise to increase total utility for both participants in the exchange. The basic concepts of rational choices based on maximizing utility ${ }^{6}$ are generally accepted even though there are differences of opinion as to what 'rational' means. Tversky and Kahneman argued that, "Because of imperfections of human perception and decision, however, changes of perspective often reverse the relative apparent size of objects and the relative desirability of options."7 In other words, people make different choices depending on how the choice is framed. Mises, on the other hand, argued, "Human action is necessarily always rational. The term 'rational action' is therefore pleonastic and must be rejected as such. When applied to the ultimate ends of action, the terms rational and irrational are inappropriate and meaningless. The ultimate end of action is always the satisfaction of some desires of the acting man." In other words, valuations are subjective and cannot be assigned objective quantities or even ranks. We cannot start from an objectively correct utility curve and determine which choices should be made; we can only observe the choices that people actually make and infer the subjective valuations based on those choices.

The above framework allows us to discuss charity as a market approach to helping the indigent who cannot afford basic essentials. While the goals of charity and government subsidized health care are both to increase health care for the indigent, the incentives for charity and government subsidized health care are quite different and lead to much different results.

\section{ChaRITABLE IMPULSE}

The origin of charitable giving dates back to antiquity. The American tradition of charity dates back to 1630. ${ }^{9}$ Most people do not like to see their neighbors suffer. There are exceptions, such as psychopaths and sociopaths, but most people feel ill when they see their neighbors suffering. If the ill sensation is large enough, most people will contribute time, effort, material goods, or money to help their neighbor. This is called charity. It appears voluntarily and spontaneously without any commands from authorities.

There are limits. If one is walking down the street and sees an elderly person stumble and fall to the ground, there is a natural impulse to lend assistance. Most people will take a little time to see if the person is badly injured. If the fallen victim can stand, many will assist the victim to their feet and guide them to a safe place to rest and recover. A fraction of these Good Samaritans will call a family member of the victim to come pick them up. A smaller fraction will call a cab and pay the fare in advance. Very few Good Samaritans, however, will offer to take the elderly victim to the ER and pay for a full evaluation with top to bottom CT scan. Fewer still would pick up the tab for a hip replacement should it be necessary.

The Good Samaritan has obligations to self, family, and friends that are higher priority. Most people will voluntarily move a little bit to the left on their own utility curve to finance a much larger movement to the right on the utility curve of someone they perceive as a victim of circumstance. We should not be surprised, however, when these Good Samaritans balk at sacrificing their future dreams to finance a liver transplant for an alcoholic. No matter what limit the Good Samaritan sets for charitable contribution, there will be public scolds claiming that the Good Samaritan should have done more; public scolds are very charitable with other people's time, effort, and property. The debate over how much is "fair" is another version of the debate whether "rational" choice is a redundancy. 


\section{Division of Labor and Charitable INSTITUTIONS}

An advanced economy exhibits division of labor. Rather than everyone producing everything that they need for their own consumption, people specialize in the production of goods in services and trade with each other. The division of labor extends to charity. The rock musician George Harrison was able to relieve far more suffering in Bangladesh by performing a rock concert and donating proceeds from that concert than he could by working in a soup kitchen delivering hot meals. George Harrison donated his time doing what he was most efficient at - making beautiful music - and used the money earned to fund the delivery of needed charity to the people of Bangladesh by other people more skilled at the delivery of charity.

The division of labor also allows many people to pool small donations into a single large charitable effort that none of the donors would be able or willing to achieve as individuals. Just as insurance allows small entrepreneurs to pool risk against catastrophic risks unaffordable by individuals, charitable institutions allow individual Good Samaritans to pool resources into the relief of a catastrophic suffering. For example, a child with leukemia who needs a bone marrow transplant costing hundreds of thousands of dollars may benefit from small charitable donations by individuals. Individual Good Samaritans who would not contribute their life savings to fund the transplant, will pool resources with other Good Samaritans and together fund the very expensive needed procedure. St. Jude Children's Hospital treats an average of 7,500 children per year in a 78 bed hospital with a budget of about $\$ 1$ billion per year funded mostly by private charitable contributions. Celebrities donate their time to help raise money to fund the delivery of health care to needy children by more than 3,600 employees. ${ }^{10}$

\section{Contrast With Government Subsidized HEALTH CARE}

Government subsidized health care pools tax payments forcibly extracted from individuals in the community to pay for subsidized or "free" health care. Although superficially similar to institutionalized charity, there are important differences between charity and government health care that lead to much different outcomes. Charitable institutions have to attract voluntary donations; they do so by offering results that make the donors happy.

Taxpayers cannot refuse tax payments on the basis that money is wasted. The metric for government health care is the amount of money spent rather than the amount of suffering relieved. The government bureaucracy is interested only in an increasing budget rather than the solution to any problem. Government would rather spend $\$ 475,000$ on monopoly profits to a pharmaceutical company like Novartis to treat a single patient ${ }^{11}$ than to spend pennies to treat hypertension with generic medications that can prevent strokes, heart attacks, cardiomyopathies and other complications in millions of people.

Charities can only attract new money from new donors by delivering outcomes that make donors feel good about the benefit of their donations. Charity will try to use its limited resources to achieve the maximum good in order to get the next batch of donations. Government prefers problems to get worse in order to demand a bigger budget.

Charity cannot make donors destitute by demanding more than donors can afford. Government has no such limits. Government can push expenditures past the point of satiety or maximal utility and make situations worse. Governments can starve and have starved entire populations by confiscation in order to provide for the politically favored. ${ }^{12}$

Charities can become corrupt, but the corruption cannot be hidden from the donors who demand relief of suffering. A corrupt charity will lose its voluntary funding and donors when the corruption becomes transparent and those donors will choose a more deserving charity for their donations. The reputation of a charity to deliver the maximum good for a limited budget is arguably the charity's most valuable capital asset. Government programs always become corrupt because the taxpayers have no other options than to keep pouring good money after bad. 


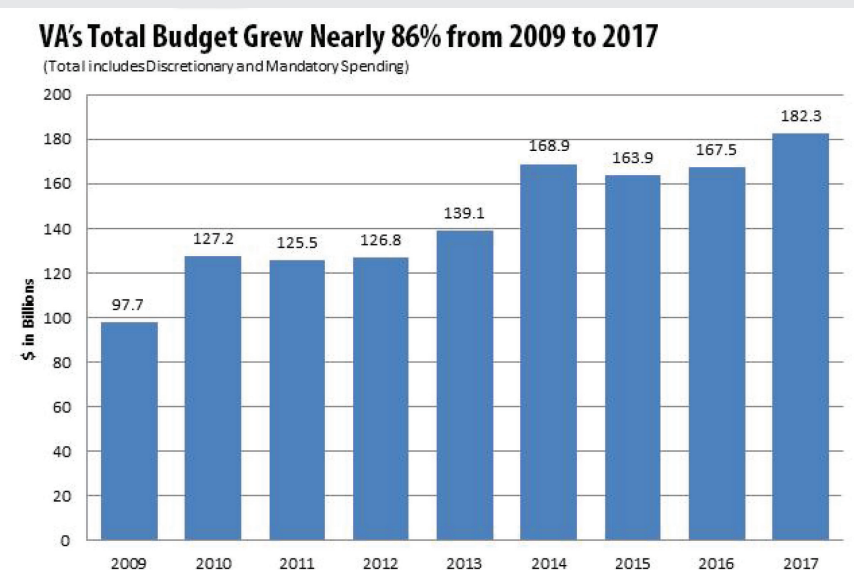

Figure 3. President Trump has proposed increasing the VA budget further to $\$ 198.6$ billion for fiscal year $2019 .{ }^{17}$

The VA system illustrates the above concepts. In January 2014 CNN broke the story about delays for up to a year in diagnostic colonoscopies. ${ }^{13}$ By April 2014 the Office of Inspector General (OIG) reported that as many as 40 veterans had died as a result in delays of care at the Phoenix VA. ${ }^{14}$ Despite federal laws enacted to "solve" the problem, in September 2017 the delays in health care for veterans continued. ${ }^{15}$ Despite claims that wait times had decreased to 17 days for new appointments, the VA was using only about half of its appointment slots, over 180,000 veterans had waited over 30 days for an appointment, and over 45,000 veterans had waited over 90 days for an appointment. Meanwhile, the VA budget continues to grow. ${ }^{16}$

\section{Greed, Charity and Government HEALTH CARE}

One justification for government health care is that private charity is not enough. It is said that government must step in when volunteerism falls short. This argument presumes, however, that public solutions will be superior to private solutions, and that government solutions will not fall short. The wants and needs of everyone can never be fully satisfied as long as we live in a world of scarcity. Public solutions can make scarcity worse as in The Tragedy of the Commons. ${ }^{18}$ The argument for government health care or government charity inevitably is an argument that the outcomes of market choices are either incorrect or irrational. This debate gets back to the previously mentioned argument whether valuations of utility are objective or subjective.

How do the Ebenezer Scrooges of the world behave with respect to private charity and government health care? A system of private charity is voluntary, so there is no way to compel Scrooge to make charitable contributions. In real life, however, a miser motivated only by personal greed will have to contribute to charitable efforts. In a competitive economy, people can buy from whomever they want. All things being equal, including price and quality, customers will prefer to buy from someone they like rather than someone they hate. In order to avoid losing customers, Scrooge will be forced to offer a price discount to prevent customers from buying from his more likeable competitor. It will be in Scrooge's best financial interest to at least make people think that he is charitable. The exception, of course, would be if government granted Scrooge a monopoly, but that is not a market phenomenon.

How does Scrooge behave in a system of government subsidized health care? The public does not like someone because they pay taxes. Scrooge does not generate any good will with customers by paying more taxes. Scrooge benefits from a government health care system by rent seeking. Rent seeking is the process of obtaining economic benefit through the political arena rather than engaging in mutually beneficial trade or the direct production of wealth. ${ }^{19}$

One form of rent seeking would be for Scrooge to obtain monopoly privilege to sell pharmaceuticals, medical equipment, or medical supplies to a health care system payer such as Medicare. The government does not care how much a medication costs; higher costs justify higher budget requests. The government health care system facilitates wealth transfers from the taxpayers to the Scrooges. The politicians seek their own rents from the rent seeking Scrooges in the form of campaign contributions. The politicians and Scrooges win at the expense of the taxpayers. Both 
the Scrooges and government have an interest in the health care problem's becoming worse. Both the Scrooges and government will be happy with an ever worsening problem's demanding an ever increasing budget and requiring ever increasing payments from the taxpayers.

\section{Conclusions}

The Law of Marginal Utility explains how small decreases in personal wealth can lead to an increase in happiness or total utility via charitable contributions. The division of labor leads to the creation of charitable institutions by entrepreneurs. Charities must compete for donations and will seek market solutions to maximize the total happiness of donors by providing the greatest relief of suffering on a limited budget. In contrast, government health care systems are like locusts that consume all available resources with complete disregard to whether any good is achieved. Like all monopolies, government health care bureaucracies are concerned with ever increasing budgets rather than with actual solutions to problems.

Article citation: Berdine G. Charity vs. government health care. The Southwest Respiratory and Critical Care Chronicles 2018;6(26):51-57

From: Department of Internal Medicine at Texas Tech University Health Sciences Center in Lubbock, Texas

Submitted: 8/10/2018

Accepted: 9/16/2018

Reviewer: Cheryl Erwin, JD, PhD

Conflicts of interest: none

This work is licensed under a Creative Commons

Attribution-ShareAlike 4.0 International License

\section{REFERENCES}

1. Berdine, Gilbert. Affordable health care: what it means and how do we fix our current unaffordable system. The Southwest Respiratory and Critical Care Chronicles, Oct. 2017. ISSN 2325-9205. doi:http://dx.doi.org/10.12746/swrccc. v5i21.415.
2. Berdine, Gilbert. Sustainable Health Insurance. The Southwest Respiratory and Critical Care Chronicles, v. 6, n. 25, p. 63-68, July 2018. ISSN 2325-9205. doi:http://dx.doi. org/10.12746/swrccc.v6i25.488.

3. Jowett, B. Politics by Aristole http://classics.mit.edu/ Aristotle/politics.7.seven.html

4. Stange KC. The Problem of Fragmentation and the Need for Integrative Solutions. Annals of Family Medicine. 2009;7(2):100-103. doi:10.1370/afm.971.

5. Stiggler, G. The adoption of the Marginal Utility Theory. History of Political Economy. Fall 1972. 4(2): 571-586. doi: https://doi.org/10.1215/00182702-4-2-571

6. Levin, J. Rational Choice Thoery. 2004. Accessed at: https://web.stanford.edu/ jdlevin/Econ\%20202/Choice\%20 Theory.pdf

7. Tversky A, Kahneman D. The framing of decisions and the psychology of choice. Science. 1981 Jan30;211(4481):453-8.

8. WhatDoAustriansMeanby "Rational"?.MisesInstitute. 2006. https://mises.org/library/what-do-austrians-mean-rational

9. A Model of Christian Charity. Teaching American History. http://teachingamericanhistory.org/library/document/amodel-of-christian-charity/

10. Facts for the media. St Jude Research Hospital. https://www. stjude.org/media-resources/media-tools/facts.html

11. FinancialTimes.https://www.ft.com/content/b97f063a-8da111e7-a352-e46f43c5825d

12. Ukraine 1933. The Terror Famine- Robert Conquest Lecture Transcript. Accessed at: https://www.ushmm.org/confrontgenocide/speakers-and-events/all-speakers-and-events/ genocide-and-mass-murder-in-the-twentieth-century-ahistorical-perspective/ukraine-1933-the-terror-famine

13. Bronstein, $\mathrm{S}$. Veterans dying because of healthcare delays. CNN Investigates. 2014 https://www.cnn.com/2014/01/30/ health/veterans-dying-health-care-delays/

14. Robbins RA. Patient deaths blamed on long waits at the Phoenix VA. Southwest J Pulm Crit Care. 2014;8(4):227-8. doi: http://dx.doi.org/10.13175/swjpcc050-14 PDF https:// www.washingtonexaminer.com/va-only-filling-half-ofits-medical-appointments-while-veterans-wait-for-weeks/ article/2634652

15. Hannel, E. VA only filling half of its medical appointments while veterans wait for weeks. Washington Examiner. Sept 2017. http://pulse.ncpolicywatch.org/2017/04/27/ trumps-proposed-4-4-billion-budget-increase-veteransaffairs-critically-needed-north-carolina/

16. Toledo, L. Trump's proposed 4.4 billion budget increase for Veterans Affairs is critically needed in North Carolina. The Progressive Pulse. Accessed at: http://pulse.ncpolicywatch.org/2017/04/27/trumps-proposed-4-4-billion-budgetincrease-veterans-affairs-critically-needed-north-carolina/ 
17. Office of Public and Intergovernmental Affairs. U.S. Department of Veteran Affairs. Accessed at: https://www.va.gov/ opa/pressrel/pressrelease.cfm?id=4007

18. Hardin, G. The Tragedy of Commons. Science 13 Dec 1968: Vol. 162, Issue 3859, pp. 1243-1248. DOI: 10.1126/ science.162.3859.1243 http://science.sciencemag.org/content/ $162 / 3859 / 1243$

19. Henderson, D. Rent Seeking. The Library of Economics and Liberty. https://www.econlib.org/library/Enc/RentSeeking. html 